\title{
A Perspective on Manufacturing ANd ENVIRONMENTAL MANAGEMENT
}

\author{
TAKAKUWA, S.
}

Abstract: The relationship between corporate manufacturing activities and the environment depends on issues related to the environment, greenhouse gases and materials and energy balance. Pollution is primarily caused by the emission of pollutants resulting from the development of industrial activities. Japan has accumulated significant experience in combating environmental problems over the past several decades. Having suffered through numerous environmental crises, the nation has responded with intensive technology developments and mass movement activities. Regarding the external environment and corporate social environmental management, sustainable development, extended producers' responsibility and environmental management might be discussed step by step. Herein, the concept of an environmental management system (EMS) for the realization of a low-carbon society is introduced. ISO 14000, EcoAction 21, material flow cost accounting and management of energy conservation are especially introduced. Most importantly, the management cycle principle is used to expound on management of the environment and energy. The relationship between environmental management and other types of management such as production/economic management, human resource management, information management, safety management is discussed from the perspective of technology management. In the process of the manufacturing and social-environmental management of an enterprise and the implementation of JK (Jishu-Kanri) self-motivated micro management activities, it is necessary to decide how to balance the relationship between manufacturing activities, the social-environmental management program and cost. It is important to enhance environmental protection awareness, especially in developing countries, to introduce environmental management systems effectively.

Professional Engineers. (in Japanese)

Keywords: manufacturing, environmental issues, environmental management systems, energy conservation
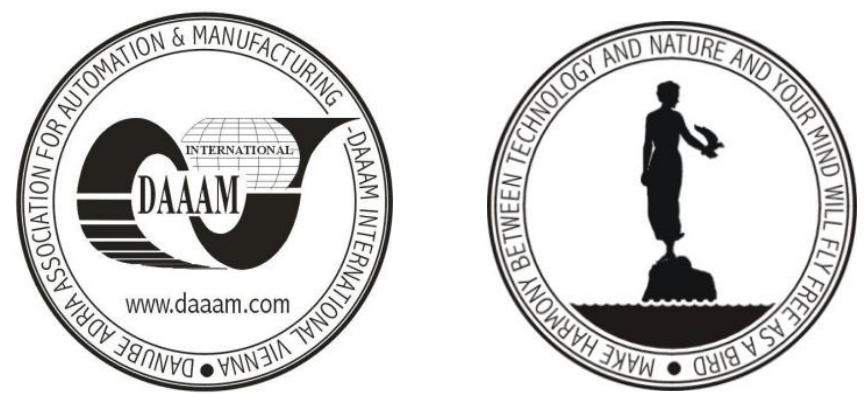

Authors' data: Prof. Takakuwa, S[oemon]; Graduate School of Economics and Business Administration, Nagoya University, Furo-cho, Chikusa-ku, Nagoya, Japan, takakuwa@ soec.nagoya-u.ac.jp

This Publication has to be referred as: Takakuwa, S[oemon] (2013) A Perspective on Manufacturing and Environmental Management, Chapter 09 in DAAAM International Scientific Book 2013, pp. 213-234, B. Katalinic \& Z. Tekic (Eds.), Published by DAAAM International, ISBN 978-3-901509-94-0, ISSN 1726-9687, Vienna, Austria

DOI: $10.2507 /$ daaam.scibook.2013.09 
Takakuwa, S.: A Perspective on Manufacturing and Environmental Management...

\section{Introduction}

Daily life and economic activities are closely related to the global environment. With the vast depletion of natural resources and energy, heavy emissions of carbon dioxide $\left(\mathrm{CO}_{2}\right)$ and other GHGs (greenhouse gases), coupled with a significant amount of waste, are released into the environment; therefore, we are confronted with a continuously increasing environmental burden that consequently exerts a negative impact on our daily lives and economic activities.

In 1997, the Third Conference of the Parties to the United Nations Framework Convention on Climate Change (COP3) was convened in Kyoto, and the proposal from developed countries for the reduction of greenhouse gas emissions was officially incorporated into the Kyoto Protocol. In recent years, global environmental awareness has continued to increase. With more attention devoted to corporate performance and the contribution of corporations to society, the impact of business operations on the environment has become a favorable gauge to measure corporate value. A heated discussion has consequently occurred regarding the external environment and corporate social environmental management (IPEJ, 2004).

(1) Sustainable development: the demand for a social environment for the world.

(2) Extended producers' responsibility: a demand related to ordinary organization activities.

(3) Environmental management: the demand for an organization.

In Japan, a sustainable society is defined as follows: "our living environment is composed of air, water, soil and life forms, all of which are interconnected and interrelated to keep the system in a healthy condition with no negative impact exerted upon this system so as to maintain a sound and healthy society."

Sustainable development represents the continuous development required to meet the demands of subsequent generations while also satisfying the demands of the modern generation. Extended producers' responsibility is defined as follows by the OECD: "after the use and disposal of the products manufactured by producers, they should be liable for the recycling and disposal of the relevant products" (OECD (www.oecd.org/)). Environmental management is the effective mitigation of the global environmental burden combined with an increase in social contribution; this principle represents the source of new environmental competitiveness and can effectively guide corporate activities.

\section{Manufacturing and Environmental Issues}

\subsection{Environmental Issues Caused by Industrial Activities}

Pollution is primarily caused by the emission of pollutants resulting from the development of industrial activities, as shown in Figure 1. For example, the combustion of fossil fuels releases air pollutants into the environment. Sewage often contains various types of toxic substances that further pollute public water areas (rivers, lakes and marinas). In addition, there are also other types of pollution, such as ground water pollution, vibration pollution and noise pollution. 


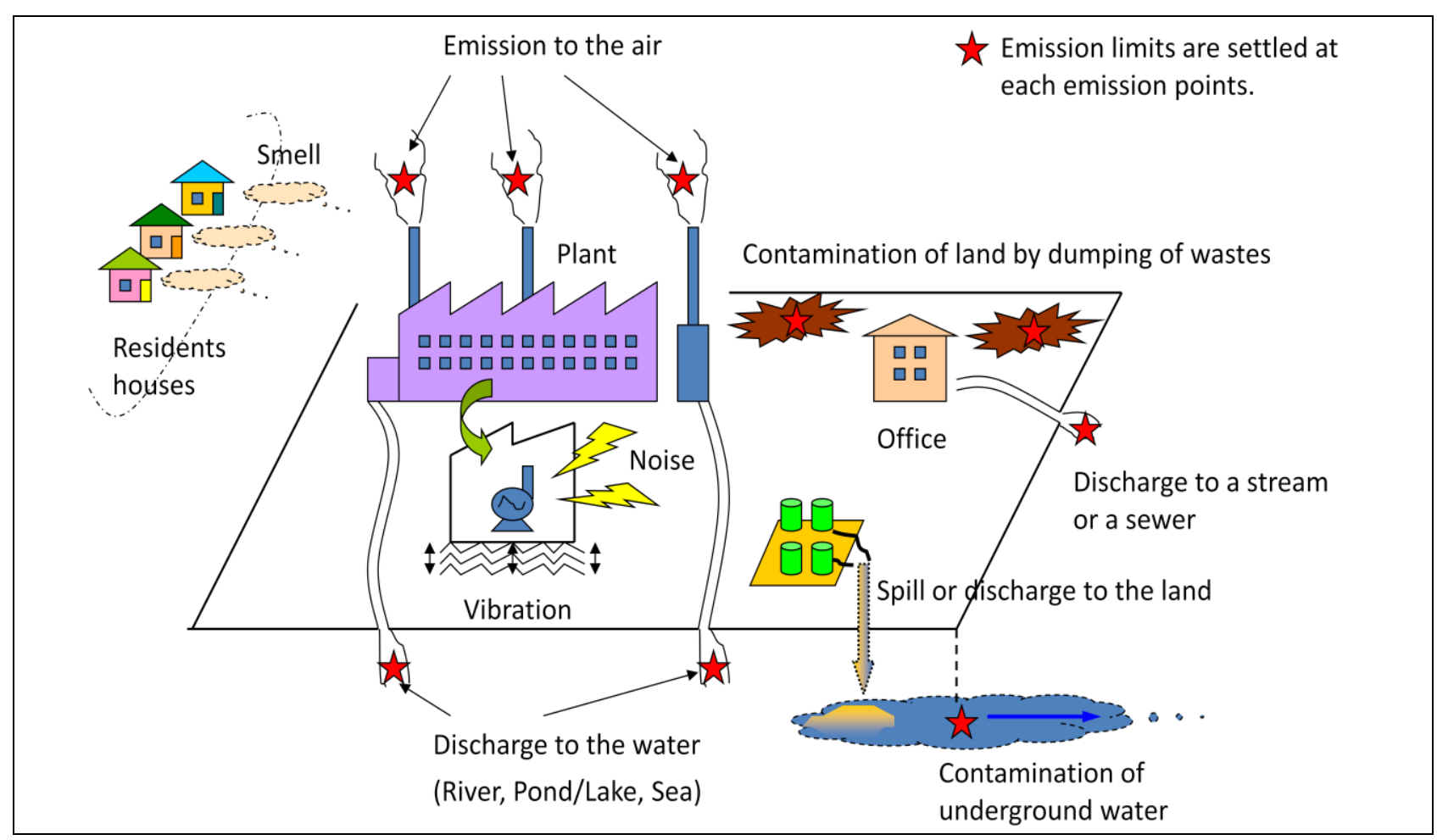

Fig. 1. Environmental Issues Caused by Industrial Activities

(Source: Ibusuki Takakuwa, 2012, p. 36)

\subsection{Public Pollution and the Associated Environmental Laws}

In Japan, because of industrial pollution in the 1960s, the epoch-defining Basic Law for Pollution Control was implemented in 1967. Good results have been achieved through continuous measures to manage pollution based on this law and related laws, such as the air pollution control law. In the 1980s, with the coming of an era during which populations began to stream into Tokyo and other large cities and automobiles became more popular, there have been increasingly more problems. In connection with the Kanemi Oil Poisoning Case in 1968, laws for the control of chemical substances were formulated in 1973. The depletion of the stratospheric ozone layer and further concerns about global warming or climate change, including the hazardous droughts around 1990, led to the formulation of the Basic Environmental Law in 1993 and laws related to chemical substances, the 3Rs (reduce, reuse and recycle wastes) and resource circulation in 2000. Laws relevant to global warming are currently being formulated.

Japan, with its high population density and vigorous economic activities, has accumulated significant experience in combating environmental problems over the past several decades. Having suffered through numerous environmental crises, the nation has responded with intensive technology developments and mass movement activities, and the beneficial results of these developments can be readily demonstrated. From a global perspective, Japan leads the world in terms of addressing environmental problems.

Figure 2 provides an overview of Japanese environmental legislation. This figure reveals that the majority of laws and regulations are backward incidences that 
were implemented in response to problems that had already become prominent. However, if more emphasis had been placed on precautionary and preventive legislation, then backward incidence legislation would have only been created after negative environmental loading had become severe, and thus, economic losses would have been reduced and the overall results would have been improved. Therefore, it is important for developing countries to learn from Japanese experience so that they do not have to resort to backward incidence countermeasures. Furthermore, it is very important for industries to avoid the temptation to maximize current interests and benefits while postponing solutions to environmental problems in those countries. According to various published materials from the Ministry of Economy, Trade and Industry (METI), Japanese environmental policies for industries are primarily based on the following guidelines, which are known as the "three pillars for solving environmental problems": (1) active development of environmental technologies, (2) provision of incentives for environmental countermeasures, and (3) formulation and strict adherence to rigorous environmental restraints. These principles will guide Japan in overcoming environmental problems and facilitating Japan's efforts to create the world's most advanced energy- and resource-conserving industrial framework.

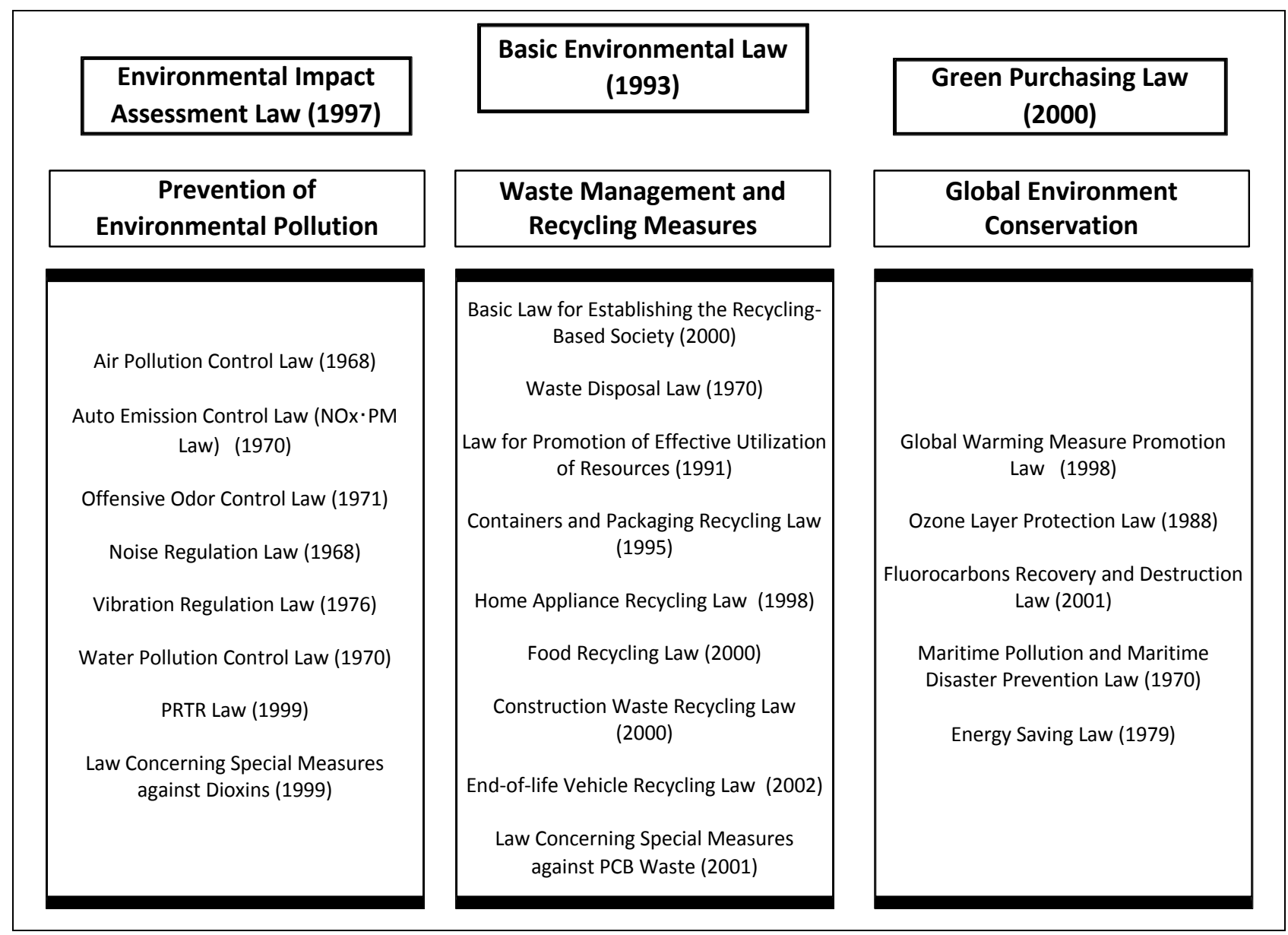

Fig. 2. Outline of Environmental Legislation in Japan

(Source: (METI (www.meti.go.jp/)))

The social economic system includes all activities of all organizations within an enterprise and all of its products and services, coupled with appropriate awareness that is established over the course of manufacturing and processing. The basic 
environmental law introduced in 1993 requires the protection of our environment against problems related to air and water quality, soil, malodorous or offensive gases, and noise and vibration. The protection of human health is the fundamental purpose of this law; therefore, it is necessary to formulate quantitative environmental standards.

In Japan, a large proportion of resources and energy for production, industrial activities and daily life activities are primarily imported from overseas markets. With respect to manufacturing plants, measures for the efficient utilization of energy, the management and protection of natural resources and the reduction of waste emissions are strongly supported by laws and regulations related to environmental energy.

\subsection{Investigation throughout the Product Life Cycle}

It is very important for us to evaluate the impact of the life cycle of relevant products and services on the environmental burden when discussing environmental issues. Generally speaking, the product life cycle consists of seven phases, including (1) resource consumption; (2) materials and parts manufacturing; (3) product manufacturing; (4) distribution; (5) sales and purchase; (6) consumption and use; and (7) disposal and recycling. Figure 3 demonstrates a typical example of a product life cycle in a recycling-oriented society.

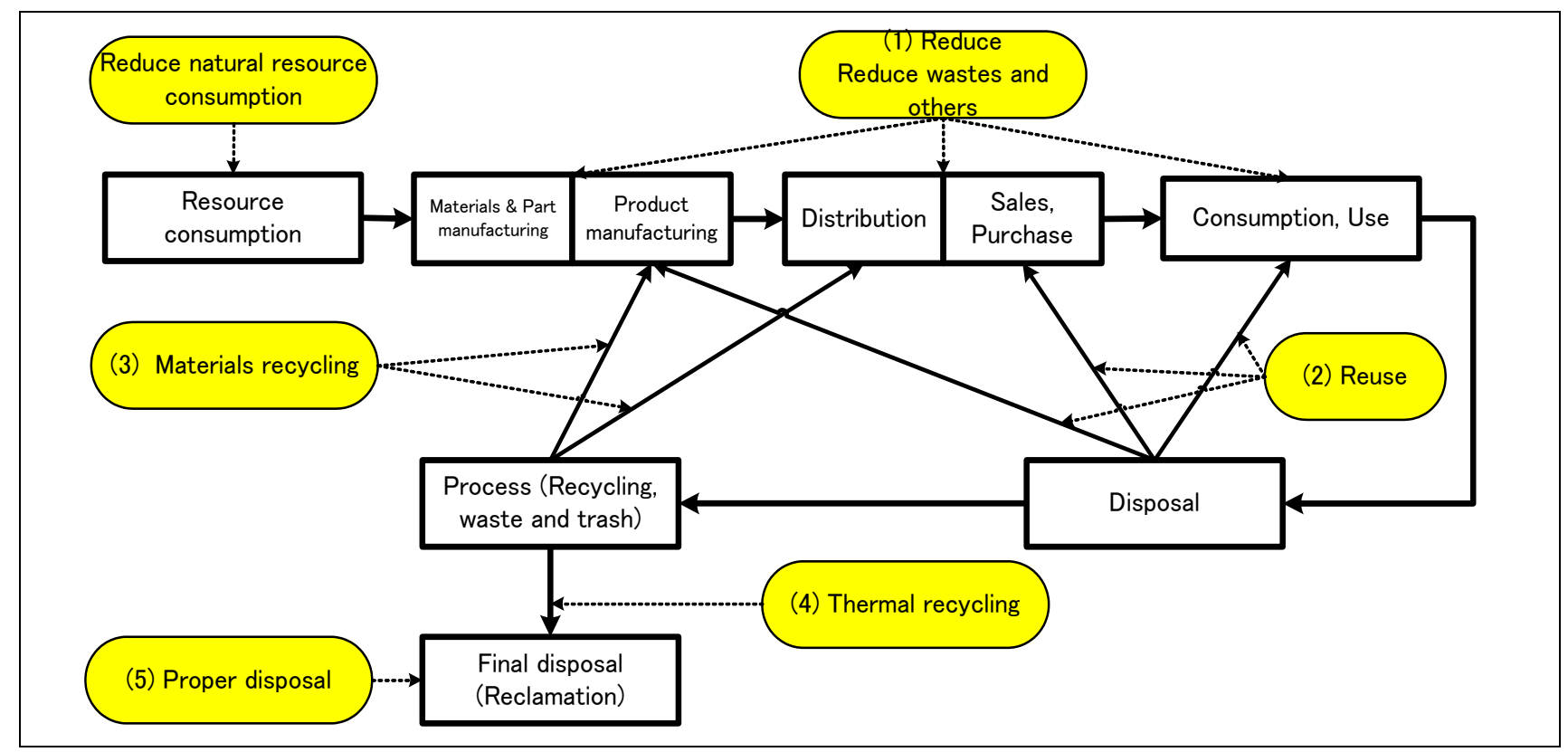

Fig. 3. Recycling-oriented Society (Source: (MOEJ, 2009) - modified)

It is of paramount importance to effectively evaluate the impacts of global warming and resource exhaustion on the entire life cycle of products; therefore, we use life cycle assessment (LCA). LCA is a technique for quantifying environmental impacts throughout a product's life cycle. Products cannot be "environmentally friendly" unless all aspects of manufacturing, from the collection of raw materials to manufacturing, use and disposal (life cycle), are examined. In 1997, a basic LCA procedure and issues report became International Standard ISO 14040. LCA is composed of several steps, including definition of the goals and scope of the 
Takakuwa, S.: A Perspective on Manufacturing and Environmental Management...

investigation, inventory analysis of the types and quantity of resources and emissions, evaluation of the environmental impacts and interpretation of the results. In addition, in the product development and design process, it is necessary to incorporate LCA data related to the environment, design for environment (DfE) and eco-design into the cost and technical data.

LCA can be used to evaluate environmental impacts such as global warming and resource depletion through an examination of product life cycles.

Today, a variety of software and databases can be used as an infrastructure for the implementation of LCA. In Japan, a national project to develop assessment methods and databases was conducted from 1998 to 2005. According to the development results, the average/generic environmental burdens of general materials were calculated and registered in this database. Against the backdrop of LCA infrastructure development, LCA has been introduced and flexibly used in voluntary environmental activities and the promotion of results in various industries.

With regard to the overall implementation of environmental design, LCA is a very important tool that aims to find room for improvement from an environmental perspective and to quantify improvements beyond the conventional product. We found that each industry, from the materials industry (upstream), parts industry (midstream), and assembly industry (downstream) to the recycling and waste treatment industry (venous system), faces individual challenges. Therefore, we will describe the cases and features of LCA by proceeding from the standpoint of various roles in the supply chain.

It is very important to focus on and reduce total $\mathrm{CO}_{2}$ emissions throughout a product's life cycle to create a low-carbon society. Instead of optimizing small parts, such as production processes, we should realize that the overall product life cycle and improvements to society as a whole should be the ultimate goal.

\section{Environmental Management Systems}

\subsection{ISO 14000}

In 1991, the BCSD (Business Council for Sustainable Development) required the ISO (International Organization for Standardization) to formulate universal standards for environmental issues in terms of a global problem: the impact of business activities on the environment.

The ISO formulated the 1996 ISO14001 environmental management system based on the BS 7750 environmental management system previously formulated by England. In fact, the ISO 14000 Series includes successive versions, ISO 14001, ISO 14004 and ISO 14005, as integral parts of the Environmental Management System. ISO 14000 is the standard formulated by the ISO for environmental management. From the perspective of global environmental protection, relevant issues must relate either to the reduction of the environmental burden or to the management of relevant activities.

In the preface to the standard, the purpose of formulating ISO 14001 is described, and some important viewpoints are introduced. 
(1) Social background in formulating the standard

Institutions shall improve environmental performance and create laws and regulations concerning environmental issues to draw the attention of stakeholders, customers, administration, mass communication, stockholders, employees, proenvironment groups and local residents to environmental issues and problems.

(2) Applicable to all organizations in all countries

Institutions should create policies and goals underlying legal requirements and consider the most significant environmental aspects. It is necessary to formulate supporting requirements in compliance with the EMS to achieve the goals of these policies. As a result, the standard is applicable to organizations of all types and scales and is suitable in all geographical, cultural and social conditions.

(3) Application of PDCA Cycling

The standard lays the foundation for a better understanding of "Plan-Do-CheckAct" (PDCA). A simple, detailed introduction follows:

Plan: Establish the objectives and the processes necessary to deliver results in accordance with the organization's environmental policy.

Do: Implement the processes.

Check: Monitor and measure processes regarding environmental policy, objectives, targets, and legal and other requirements and report the results.

Act: Take action to continually improve the performance of the environmental management system.

(4) Participation of upper management and participation by all members

The success of this system necessitates a commitment by institutions and organizations, particularly upper management, factory managers, heads of laboratories and other responsible persons within the system because their participation is the key to success. When a resolution is adopted by upper management, all members are motivated to participate.

(5) Implementation of the best available techniques

It is expected that the involvement of all stakeholders will yield the best results by applying a series of EMS regulations; however, we cannot guarantee the best results with respect to the environment. Therefore, cost effectiveness is a key factor and must be evaluated to achieve environmental objectives. Moreover, it is suggested that institutions adopt the most suitable and economically feasible technique.

(6) The EMS varies from organization to organization

The EMS is detailed and complex, with extensive documentation, and relies on the systematic applicable scope of the resources provided, the scale of the organizations and their activities, and the nature of the products and services; these factors constitute the conditions for the EMS.

In terms of the purpose and target of the environmental policy, the top management and operation executives of the company will create the implementation and correction framework, which is of particularly vital importance (Central Technology Support Center, 2003).

\subsection{EcoAction 21}


Takakuwa, S.: A Perspective on Manufacturing and Environmental Management...

There are some environmental management systems designed for specific purposes. The Ministry of the Environment, Japan (MOEJ) organizes the formulation of "the environmental activity evaluation program" for various entrepreneurs in small- and medium-sized institutions, allowing them to pay more attention to relevant matters and take targeted actions. According to EcoAction 21, it is preferable to introduce a certification and registration system into the environmental management system.

To strongly encourage small- and medium-sized institutions to pay more attention to the environment, it is necessary to effectively implement environmental protection measures, and the Ministry of the Environment has established a certification and registration system for EcoAction 21 in the environmental management system. EcoAction 21 encourages the improvement of environmental protection awareness through environmental activities. Figure 4 provides a checklist related to greenhouse gas emissions (focusing on carbon dioxide emissions).

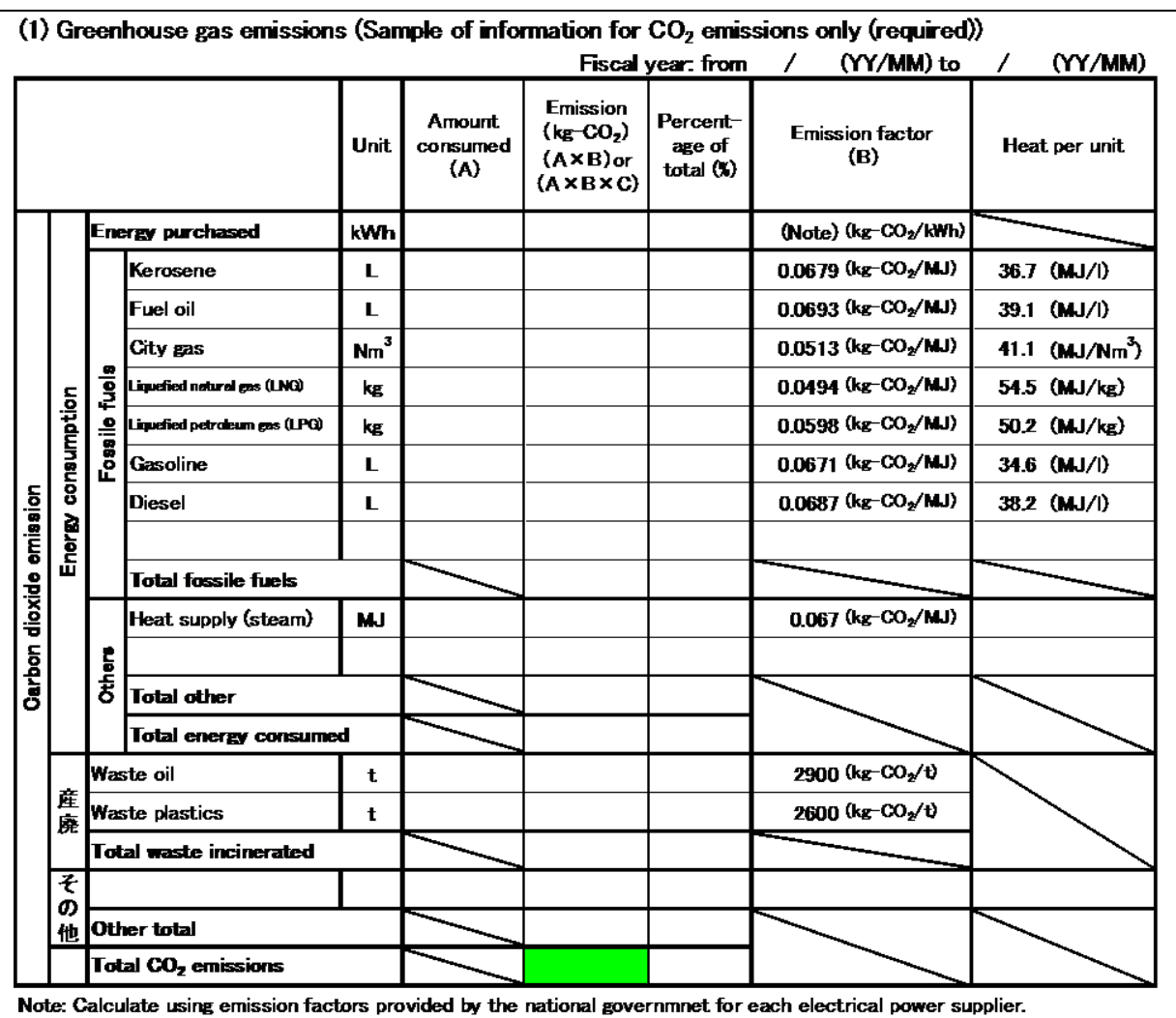

Fig. 4. Selected Part of $\mathrm{CO}_{2}$ Emissions in the List of Indicators for Each Burden (Source: (MOEJ, 2009 (http://www.env.go.jp/))

Enterprises occupy a significant position in modern society and the economy. Almost all products and services purchased and used by consumers and entities are provided and supplied by enterprises. For example, electrical and electronic goods and cars are produced by enterprises. To "green" the social economy, we must pay attention to environmental considerations in corporate activities, including products and services, and the implementation of "Environmental Management." "Environmental Management" refers to management related to environmental awareness. An EMS is essential for that purpose. 
In addition, if an enterprise pays attention to environmental issues and reduces its consumption of resources and energy, it can substantially improve the production efficiency and yield, which will contribute not only to the enterprise's sustainability but also to high valuation by customers and/or other stakeholders.

It is not sufficient for an enterprise to only consider environmental issues by reducing the environmental burden of production (e.g., by reducing the consumption of resources and energy or waste emissions). The enterprise must also consider whether its environmental activities and major business lines are rational and efficient, whether the EMS is included in organizational management systems, whether environmental risks are managed, and whether environmental management is also carried out with regard to the enterprise's products and services.

Eco-Action 21 is composed of four parts: the EMS, an environmental activity report, a self-checklist of the environmental burden, and a self-checklist of environmental initiatives. The Eco-Action 21 guidelines are conducive to promoting business while promoting the greening of the social economy. The features of EcoAction 21's guidelines, registration and certification are listed below:

\section{(1) Easy implementation of EMS by SMEs}

(2) Requirements for necessary environmental initiatives

(3) Required environmental communication

(4) Third-party evaluation of an organization's active and voluntary initiatives

The EMS in Eco-Action 21 is based on the PDCA cycle, i.e., formulation of the plan (plan), implementation of the plan (do), activity review and evaluation (check), and overall evaluation and review (act), and is composed of 13 items. By repeated implementation of the PDCA cycle, organizations can also improve their environmental innovation results and continually improve the EMS. From an operational perspective, enterprise operators should aim to achieve comparatively greater environmental economic efficiency in addition to reducing the total environmental burden. To implement environmental management and enhance environmental performance, it is necessary to establish environmental indicators.

\subsection{Material Flow Cost Accounting}

Material flow cost accounting (MFCA), an environmental accounting method, was originally developed by an institute in Germany, IMU (Institut für Management und Umwelt), in the late 1990s. Then, in 2000, the Ministry of Economy, Trade and Industry (METI) in Japan started to investigate the possibility of introducing MFCA into Japanese companies. Under the guidance of METI, several companies (e.g., Nitto Denko Corporation and Canon Inc.) introduced MFCA into their management systems experimentally, becoming pilot companies for practical MFCA. In 2004, METI initiated a project to promote the dissemination of MFCA into enterprises throughout Japan (METI, 2007).

In September 2011, ISO 14051 was published, and MFCA was internationally standardized. MFCA was established as one of the Japanese Industry Standards in 
Takakuwa, S.: A Perspective on Manufacturing and Environmental Management...

March 2012. ISO 14051 clarifies the basic concept, the calculation method, and the steps for implementing MFCA. The main purpose of the standard is to indicate the principle of MFCA; detailed steps for its introduction or implementation are omitted. The contents of ISO14051 are shown in Table 1.

\begin{tabular}{|l|l|}
\hline Items & Contents \\
\hline Title & $\begin{array}{l}\text { Environmental management - Material flow cost accounting - General } \\
\text { framework }\end{array}$ \\
\hline Contents & $\begin{array}{l}\text { 1. Scope } \\
\text { 2. Terms and definitions } \\
\text { 3. Objectives and principles of MFCA } \\
\text { 4. Fundamental elements of MFCA } \\
\text { 5. Implementation steps of MFCA } \\
\text { Annex A Difference between MFCA and conventional cost accounting } \\
\text { Annex B Cost calculation and allocation in MFCA } \\
\text { Annex C Case example of MFCA }\end{array}$ \\
\hline
\end{tabular}

Tab. 1. Contents of ISO14051 (Source: Kokubu and Tachikawa (Takakuwa, 2012, p. 276))

MFCA specifically focuses on material flow and highlights the idea that nonproduct outputs or material losses are also products of the same process through which marketable products are produced. The consideration of non-product outputs or material losses as products means that attention should be paid to the costs of producing them as well. MFCA visualizes the cost of producing non-product outputs or material losses and thus highlights areas where the potential to improve exists. Companies can reduce costs by reducing the input and thus reduce losses. A reduction in the amount of materials used reduces the environmental burden of the industry (METI, 2002).

Because it is a novel technique that measures both good products and material losses in the amount of materials, MFCA must be implemented in cooperation with the other departments in a company. Ideally, all people involved in producing a product should understand the basic principle of MFCA and its benefits, and every department should participate. ISO 14051 declares that the following expertise is particularly relevant to the implementation of MFCA:

(1) Operational expertise from design, procurement, and production regarding the flow of materials and energy use throughout the organization;

(2) Engineering and/or technical expertise on the material balance implications of processes, including combustion and other chemical reactions; 
(3) Quality control expertise on issues such as the product's rejection frequency and causes and reworking activities;

(4) Environmental expertise on environmental aspects and impacts, waste types, and waste management activities; and

(5) Accounting expertise on cost accounting data and practices, e.g., cost allocation.

In collecting information to implement MFCA, it is necessary to consider the availability of data, their compatibility with MFCA, their accuracy, and the cost of data collection. These factors often exist in trade-off relationships; we must make comparisons and balance the allocation of resources among them.

In Japan, ISO 14001 is the most popular standard in the ISO 14000 family. ISO 14051, which is the international standard of MFCA, complements ISO 14001 and the other standards in the ISO 14001 family and vice versa. In particular, Japanese companies have been thought to have room for improvement in terms of utilizing EMS in accordance with economic evaluations. Compensating for this shortcoming, MFCA takes both environmental and economic aspects into consideration and provides highly useful information on decision-making to enhance profitability.

Moreover, the complementary relationship between ISO 14051 and international standards other than the ISO 14001 have also attracted considerable attention. For example, ISO 14064 and ISO 14065, which are related to managing the emission of greenhouse gases, can be implemented with MFCA to evaluate energy use based on financial information, which is helpful in reducing emissions.

\section{Management of Energy Conservation}

\subsection{Energy Conservation Law}

To achieve sufficient energy conservation, management skills need to be wellestablished in a company. In terms of energy management, the Energy Conservation Law of Japan (Rational and Relevant Laws on Energy Use) (hereinafter referred to as "the EC Law") is the most useful tool (ECCJ (www.asiaeec-col.eccj.or.jp/). This law is a comprehensive system for energy efficiency and conservation in energy use, and it has strongly promoted energy conservation in Japan. This law currently covers four fields, including factories and workplaces, buildings, transportation, and machinery and equipment. In each area, this law has devised effective measures for energy conservation and has played important roles in the promotion of energy efficiency and conservation. Furthermore, this law has a system for the qualification of energy managers and is connected to a reporting system for GHG emission.

After the first oil crisis of 1973, the EC Law was formulated in 1979 to ensure the rational use of fuel resources. This law covers factories, transportation, buildings and machinery equipment. The EC Law is globally reputed to be a highly developed legal system. The construction of the law is superior: the regulations specify not only the rule but also the energy conservation measures for operators. If the operators conduct specific measures according to the law, they will achieve further energy conservation. In this respect, the EC Law is regarded to be an excellent guidance document for operators. 
Takakuwa, S.: A Perspective on Manufacturing and Environmental Management...

In the law's introduction, the objective is described as follows: "This law aims to contribute to the sound development of the national economy through implementing necessary measures for the rational use of energy in factories, buildings, transportation, and machinery and equipment, and other necessary measures to comprehensively promote the rational use of energy, while it seeks to ensure the effective utilization of fuel resources that would meet the economic and social environment of energy at home and abroad" (Table 2).

\begin{tabular}{|c|c|}
\hline $\begin{array}{l}\text { (1) Manufacturing plants and } \\
\text { business locations }\end{array}$ & $\begin{array}{l}\text { - Factories } \\
\text { - workplaces (hospitals, hotels, schools, etc) }\end{array}$ \\
\hline (2) Transportation & $\begin{array}{l}\text { - Carriers } \\
\text { - Consigners }\end{array}$ \\
\hline $\begin{array}{l}\text { (3) Residential buildings and } \\
\text { structures }\end{array}$ & $\begin{array}{l}\text { - Construction client of residence/building } \\
\text { - Owner/manager of the residence/building }\end{array}$ \\
\hline (4) Machinery and appliances & $\begin{array}{l}\text { Manufacturers and importers of machinery and equipment } \\
\text { consuming energies }\end{array}$ \\
\hline
\end{tabular}

Tab. 2. Scope of Regulations under the EC Law of Japan (Source: Taniguchi (Takakuwa, 2012, p. 94))

This statement shows the importance of the effectiveness or efficiency of the development of the economy and energy use as well as the importance of their harmonization or compatibility. The term "energy" in this law means fuels, such as oil, flammable natural gas, and coal, as well as the heat and electricity produced by using such fuels, excluding renewable energy, such as the electricity generated by photovoltaic cells, wind power, or biomass. A company that owns and operates factories or workplaces with annual energy usage amounts over 1,500 kL-crude oil (converted to primary energy) is designated as a "Specified Business Operator" by the EC Law. Furthermore, the company is obliged to submit a "medium-to-long term plan" and a "periodical report" on the status of its energy utilization every year to the appropriate minister. Additionally, a specified business operator is required to appoint "energy managers" who coordinate energy management in factories that use total annual energy amounts of over 1,500 kL-crude oil (converted to primary energy). Energy conservation can be executed in various and continuous management steps, i.e., the PDCA cycle.

\subsection{Energy Conservation in Terms of Management}

\subsubsection{Qualification for Personnel}

To promote energy-saving activities, human resources with good understanding and energy-saving technology are undoubtedly an important factor. The EC Law requires a designated factory to appoint an energy manager. The EC Law has a qualification system for energy management personnel to foster effective and reliable energy management, promote competent energy management personnel and establish 
confirmed energy management work positions. A certification for the qualification is given by the state to people who have passed the national certification examination authorized by the EC Law.

The energy manager considers the energy conservation plans of factories. However, senior management participation and judgment are crucial for the introduction of large-scale energy conservation facilities and transformation of the energy conservation awareness of the company. The tasks of the management control officer include 1) organizing promotional activities from the viewpoint of operators, 2) establishing medium- and long-term plans, and 3) establishing management personnel for site-related projects and executive programs.

\subsubsection{Visualization and Goal Setting}

Properly understanding the current energy usage is fundamental to energy conservation. The EC Law requires specific operators to submit a periodical report on their annual energy usage to the regional bureau of the Ministry of Economy, Trade and Industry and related authorities by the end of July of the following year. The report must include a record of energy consumption, energy unit consumption and future expectations, the situation of energy consuming facilities and compliance with standards.

The energy unit consumption is calculated as follows:

Energy unit consumption $=(\mathrm{A}-\mathrm{B}) / \mathrm{C}$

where

A: energy consumption (fuel consumption and consumption of heat and electricity provided by others)

$\mathrm{B}$ : energy sold to other companies

$\mathrm{C}$ : values closely related to energy consumption

$\mathrm{A}$ and $\mathrm{B}$ will be converted by crude oil.

Developing a medium- and long-term energy saving plan is as important for an operator as developing a corporate sales and production plan. Therefore, the EC Law requires specific operators to develop and submit their medium- and long-term plans. According to Article 14 of the EC Law, specific operators and specific chain-style businesses must create medium- and long-term plans (3-5 years). The energy saving target should be as follows: "factories or operators and other operating units shall improve their medium- and long-term energy consumption units by an annual average of $1 \%$." The equipment types are listed by established standards.

In addition, the top runner program establishes energy performance baseline values (Top Runner Standard) for manufacturing enterprises. Enterprises should produce products that exceed the baseline values. For example, fuel economy standards for cars, energy conservation baseline values for oil and gas equipment 
(e.g., home appliances and office equipment) should have the best energy efficiency performance among current instruments.

\subsubsection{Improvement activities}

"The Standard of Judgment for Business Operators" was established to achieve the rationalization of fuel combustion, the utilization and recovery of waste heat, and the prevention of electricity loss by resistance, among other objectives. As explained above, the EC Law of Japan has played very important roles in promoting energy efficiency and conservation.

Furthermore, the experience of Japan in energy efficiency and conservation under the EC Law of Japan is very useful knowledge for countries that need and require the implementation of institutional systems to promote energy efficiency and conservation. The EC Law of Japan has implemented an energy management system in Japan, which has contributed to the drafting process of an international management system for energy management (ISO 50001) based on energy management experience.

\section{Environmental Management in Management of Technology}

\subsection{Management of Technology and Environmental Management}

The issue in this section entails a comprehensive judgment of overall enterprise manufacturing and technology in addition to the management technology of each operation or process in manufacturing activities and projects. To be more specific, it is necessary to have comprehensive management and judgment of the complete operation when making a decision. Figure 5 indicates that production/economic management, human resource management, information management, safety management and social and environmental management should be effectively conducted from the perspective of technological management. 


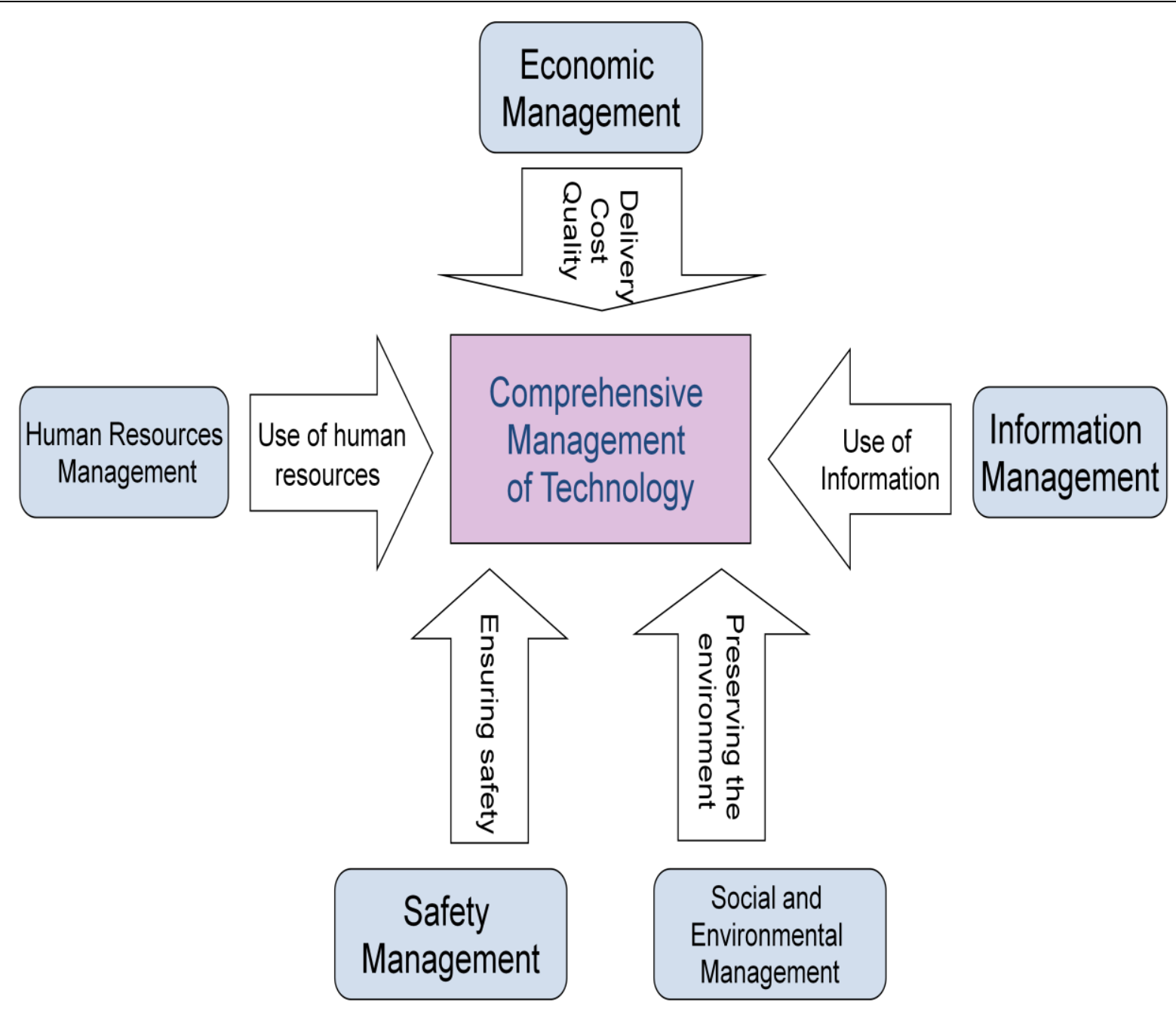

Fig. 5. Comprehensive management of technology (Source: (IPEJ, 2004) - modified)

\subsection{Human Resource Management}

To promote environmental and energy conservation activities within enterprises, it is necessary to cultivate and train pollution control managers, energy managers and qualified personnel for energy management and other professional holders of relevant qualification certificates related to environmental energy.

In addition, pollution control management and the associated system play a significant role in addressing industrial pollution. The first resource for pollution control is the general manager. Leaders of businesses (such as factory leaders) who are responsible for production should serve as the general manager for pollution control, and they do not need to acquire national qualifications. The secondary resources are the chief pollution control manager and the pollution control manager, who must obtain a national license. Pollution control managers are engaged in facilities, focus on pollution control and assume important technical positions. In large businesses, it is necessary to have a chief pollution control manager between the general manager and the pollution control managers. As shown in Figure 6, factories and business organizations have established pollution control organizations, including 
Takakuwa, S.: A Perspective on Manufacturing and Environmental Management...

a general manager of pollution control and a chief pollution control manager. There are also pollution control managers in various fields JEMAI ( http://133.242.7.244/english/index.html/).

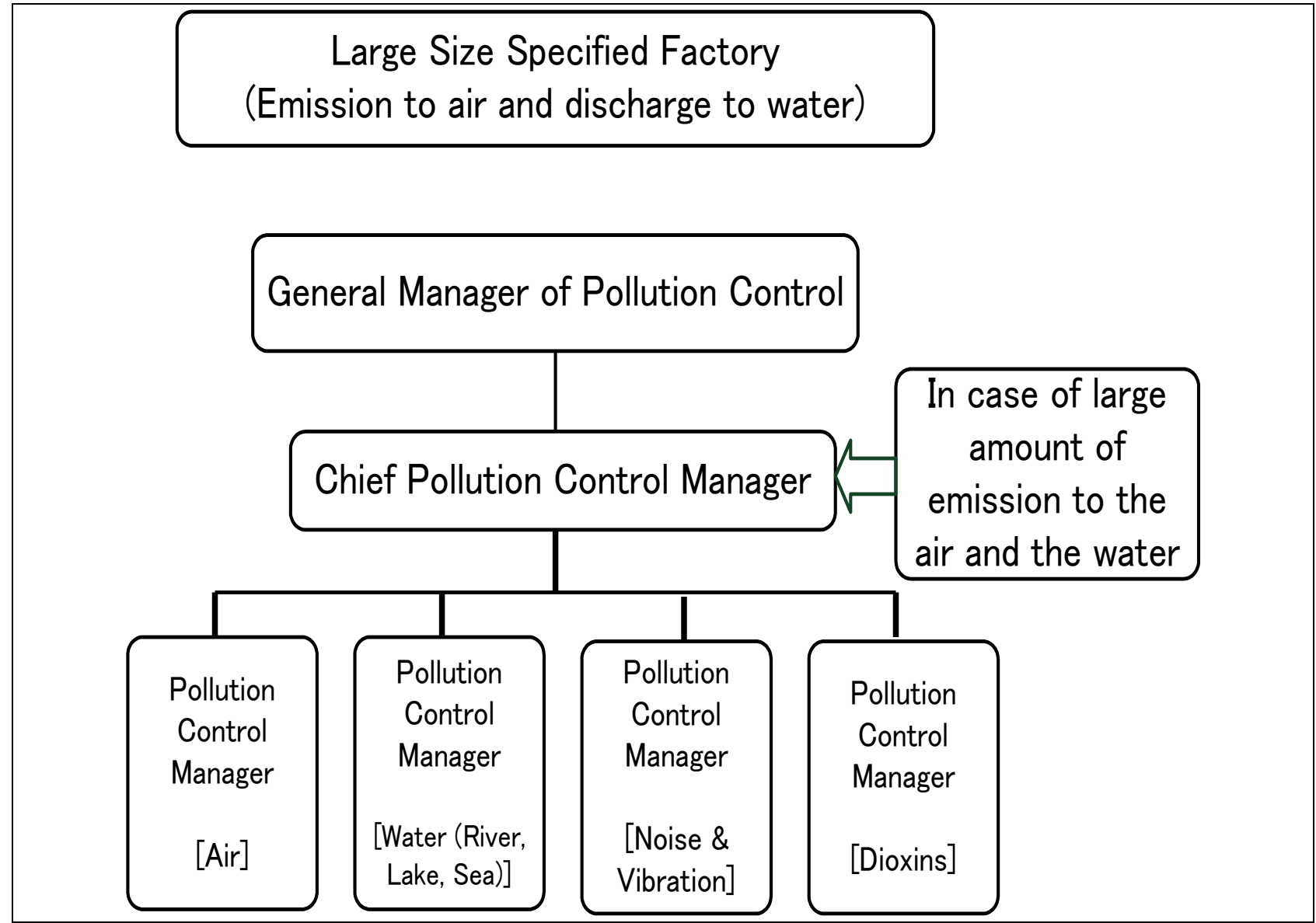

Fig. 6. Pollution Control Organization (source: Ibusuki (Takakuwa, 2012, p. 43))

Second, to promote energy-saving activities, human resources equipped with good understanding and energy-saving technology are undoubtedly an important factor. The EC Law of Japan has a qualification system for energy management personnel to foster effective and reliable energy management, promote competent energy management personnel and establish certified energy management work positions. A certification for qualification is given by the state to individuals who have passed the national certification examination authorized by the EC Law. The energy manager considers the energy conservation plans of factories. However, senior management participation and judgment are crucial for the introduction of large-scale energy conservation facilities and transformation of the energy conservation awareness of a company. A type 1 energy manager is a person with certification from the state. A type 2 energy manager and energy management planning promoter is a person with certification from the state or a person who has attended an authorized energy management seminar. The nomination of energy managers is illustrated in Figure 7 ECCJ ( http://www.eccj.or.jp/). 


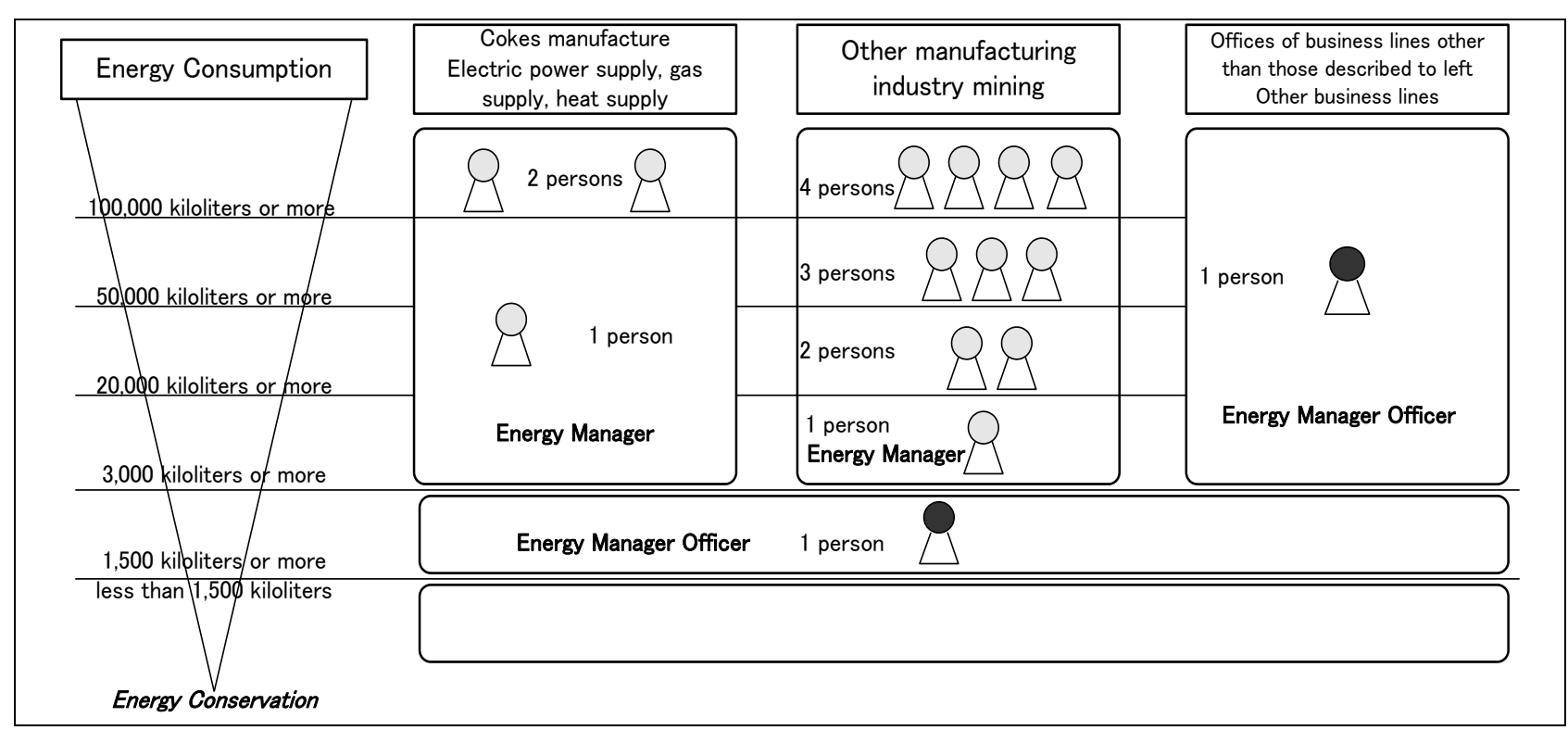

Fig. 7. Nomination of Energy Managers (source: Taniguchi (Takakuwa, 2012, 98))

Furthermore, to more effectively manage the implementation of the environmental management systems of the relevant organizations and to enhance the environmental awareness of the involved staff, it is necessary to establish cultivation and training mechanisms. Most importantly, enterprise operators, managers and staff must have a good understanding and command of relevant knowledge to enhance the environmental awareness.

\subsection{Information Management}

In general, the information communicated to external organizations can be divided into undisclosed, confidential information and information that will be disclosed in the form of a clear statement for accountability or PR purposes; this information should be determined by the organization based on open or non-open judgment. Environmental accountability requires the organization to provide an external report related to relevant matters, which specifically includes the relationship between society and nature and the relationship between the society and the environment within the organization's area. Environmental accountability epitomizes corporate social responsibility and compliance of the organization or enterprise and should be published at the appropriate time.

Information from the environmental accounting process is disclosed to the public in the form of an environmental report that enables people other than employees of the enterprise to have a better understanding of the supporting contents of the environmental protection plan of the enterprise and to enhance societal trust in the enterprise. EcoAction 21, in particular, can be combined with the environmental activity evaluation program and may enable to participate in simple environmental protection activities. Furthermore, EcoAction 21 also serves as an announcement of the achievements of relevant protection activities to the public.

During the implementation of the environmental management program, a considerable amount of data is generated and demands immediate processing; therefore, IT technology is indispensable. For example, companies can use their own 
data as well as published, generic environmental data. However, to implement more reliable LCA, important data should consist of actual business partner data rather than generic environmental data. However, the basic infrastructure for the implementation of LCA (database and software), which has been a barrier for companies interested in introducing LCA, must be improved. Efforts must be made to continually improve the LCA infrastructure so that companies can utilize it more effectively.

\subsection{Safety Management}

At the operation field or site where hazardous chemicals are to be disposed of, it is very important to effectively implement occupational health and safety assessments within the management system.

The corporate stakeholders related to the enterprise or organization should communicate information related to the nature and importance of each risk, the degree of risk and the control solution (risk communication); stakeholders must also evaluate public acceptance of the risks related to environmental issues. The proper decision should then be made accordingly.

The chemical industry expends a great deal of resources and energy. In addition, it is a sector that produces heavy emissions of exhaust gas, draining and wastes and has faced a variety of pollution problems that have exerted a profound impact on human health and the environment. The Strategic Approach to International Chemical Management (SAICM) is a global policy framework that was created to foster the sound management of chemicals. Chemicals should be produced and used in ways that minimize adverse impacts on the environment and human health. Chemical management will be an important and unavoidable challenge for chemical companies in the coming decade as the world moves toward low-carbon societies. Although today we have a deeper understanding of the problems and have taken preventive actions, many problems remain. Most developed countries, including Japan, have accumulated much experience in solving problems caused by pollution and accidents. Those experiences should not be repeated in developing countries. Problems that cannot be addressed by government regulations should be solved by the voluntary action of local chemical companies.

In addition, the RoHS (restriction of hazardous substance) directive restricts the use of specified hazardous chemicals in electrical appliances and electronics products sold in EU markets. To establish a mechanism under which the specified hazardous chemical substances should not be used in products, we hereby introduce functions of the quality management system, particularly related to development and design departments, material procurement departments, acceptance inspection departments and manufacturing departments. Fundamentally, management is responsible for the mutual cooperation between relevant departments, particularly those related to technology, materials, quality and manufacturing; supplier management can reinforce this cooperation. It is very important to incorporate capital, employees and strategies developed in-house into the management framework.

\subsection{Trade-off between Manufacturing/Economic Management and Social and Environmental Management}


Figure 8 (from left to right) shows, from top to bottom, the input of energy and the output of the environmental burden with a series of input substances created by manufacturing activities and provides the basic framework for the basic factors that should be considered.

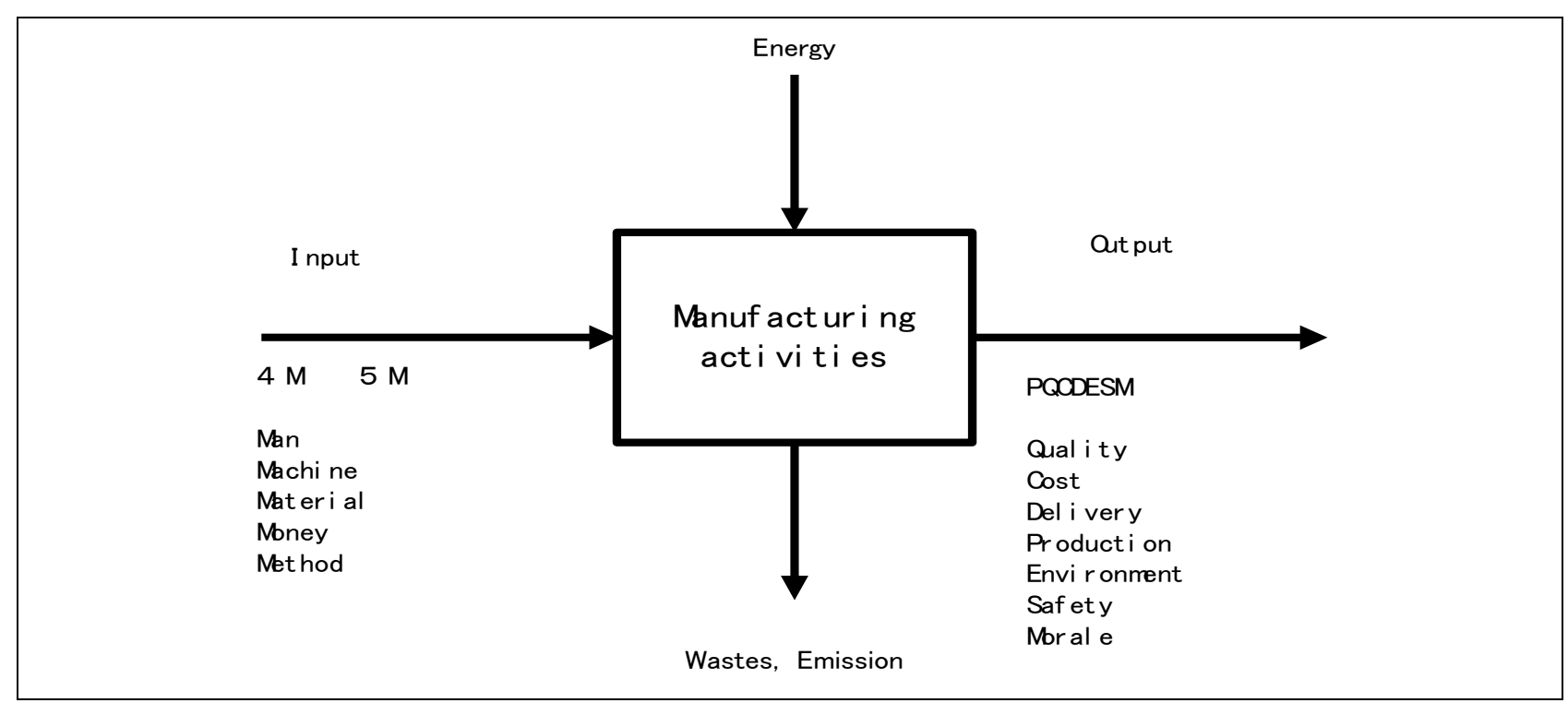

Fig. 8. Manufacturing activities

The management of quality, cost and content delivery closely related to manufacturing activities is primarily based on manufacturing and economic management. In the process of the manufacturing and social-environmental management of an enterprise and the implementation of JK (Jishu-Kanri) selfmotivated micro management activities, it is necessary to decide how to balance the relationship between manufacturing activities, the social-environmental management program and cost. During this process, the target value should be set, particularly "the top runner program". Consequently, similar enterprises should have effective environmental management programs and should improve their own energy consumption.

\section{Measures for Environmental Issues}

\subsection{Some Measures for Environmental Problems}

Strong governmental support related to environmental policy, consisting of regulations targeting the global warming problem coupled with mediation among industrial sectors and different enterprises, will play a vital role in strengthening the supporting management of enterprise environmental problems. Most importantly, industry groups spearheaded by the Nippon Keidanren-Japan Business Federation play a central role. The industry groups that represent the enterprises in the industrial sector formulate the relevant plans that the enterprises will implement to "independently" manage and find solutions for environmental problems. In recent years, research and development related to environmental operation and management has gained increasing attention. The development of environmental technology is difficult for each enterprise involved, and the government should provide support and 
assistance that are needed. At the same time, research and development requires industrial, academic, and government cooperation as well as cooperation from NPOs.

\subsection{Understanding the Social Cost Related to the Environment}

The external cost from $\mathrm{CO}_{2}$ emissions and the production of other wastes is referred to as the "social cost." Figure 9 illustrates the relationship among corporate cost, lifecycle cost and energy consumption. The impact of factors such as losses related to environmental problems affecting the external environment of enterprises, taxes and regulations related to the internalization of external diseconomies will increase the cost burden to the enterprise involved.

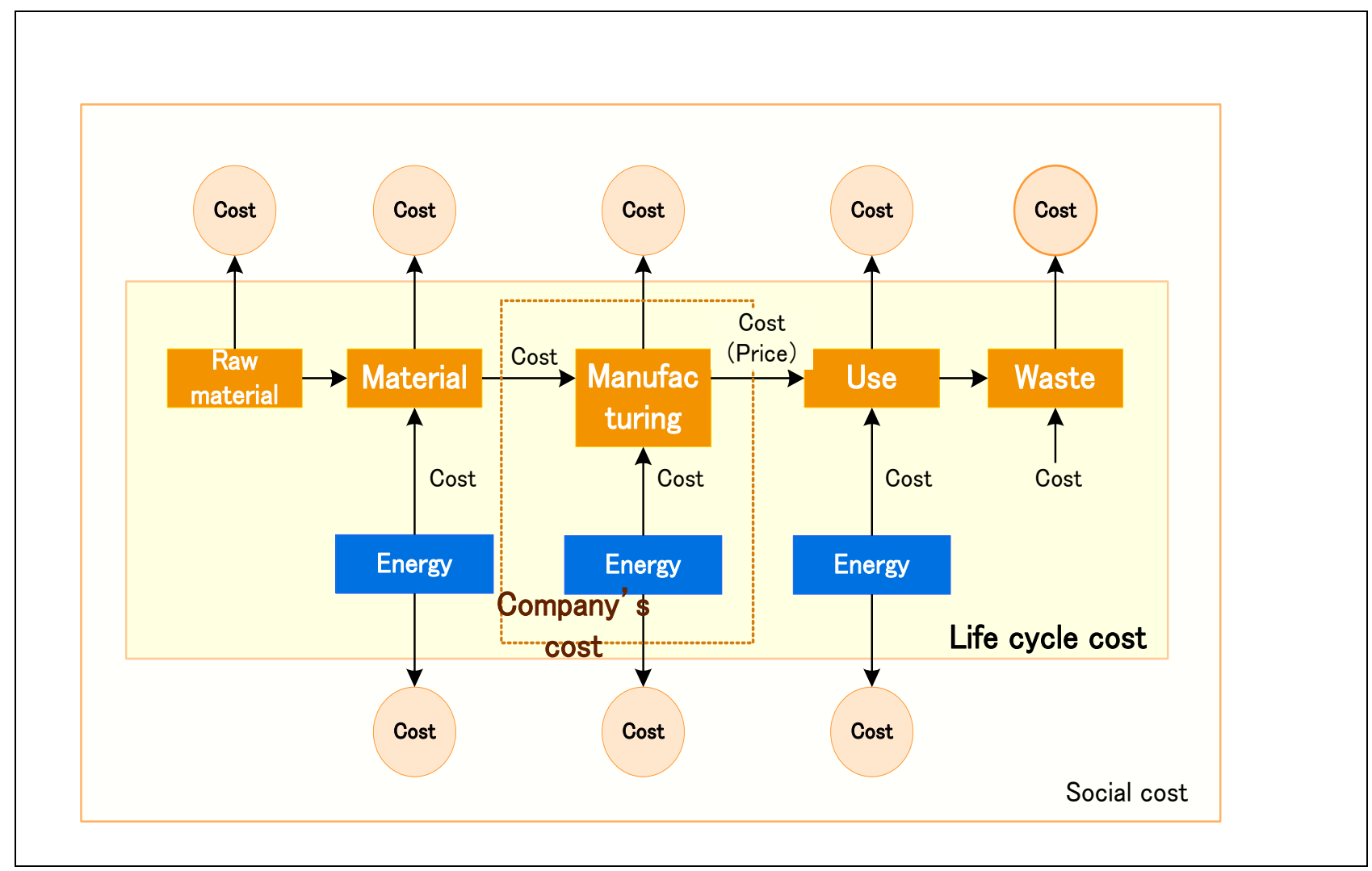

Fig. 9. Social Cost (Source: (METI, 2002, p. 182))

As enterprises consume environmental resources, the considerable emission of polluting substances and wastes will place a heavy burden on the external environment; therefore, an economic theory that specifies that enterprises should pay taxes and provide compensation for the use of environmental resources has been proposed.

Consequently, societal costs may be significantly reduced by adherence to this theory. However, the social costs are not restricted to a single country. Because of global competitiveness between developed countries and emerging and developing countries, these types of countries bear environmental societal costs at different levels relative to developed countries. Therefore, those countries with a higher environmental protection level should pay a greater proportion of the social costs incurred by other countries with a lower environmental protection level. A survey conducted by Professor Zhanwen Niu of Tianjin University reveals that a 
considerable number of Chinese enterprise operators and managers believe that environmental issues are simply "external problems" and that the wastes discharged by enterprises should not be directly associated with the enterprises. In addition, reducing pollution and managing wastes is a large burden for enterprises to assume. According to enterprise operators and managers, environmental protection is "a public welfare program"; however, enterprises should give top priority to the pursuit of the maximal economic benefits. Alternatively, investors, in general, show no interest in environmental protection ( $\mathrm{Niu}$ and $\mathrm{Fu}, 2012$ ). However, enterprise operators and managers should be aware that they cannot perform environmental management and energy conservation successfully unless they increase environmental protection awareness.

\section{Conclusion}

From 1950 to the present, Japan has overcome and solved a variety of environmental issues, namely, industrial pollution and domestic waste problems and the global environmental problem, and Japan has also paid close attention to global environmental issues and has formulated or promulgated corresponding policies and regulations. Given the development and popularization of sophisticated technology, we can continue to formulate and update countermeasures to achieve better global environment protection in Japan. Hence, based on the research and experience on environmental management and energy conservation in Japan, a perspective on manufacturing and environmental management was described.

The concept of an environmental management system for the realization of a low-carbon society was introduced. The management cycle principle was used to expound on management of the environmental and energy. The relationship between environmental management and other types of management, i.e., economic/manufacturing management, human resource management, information management and safety management, was discussed, especially from the perspective of technology management. In particular, the need for balancing the trade-off between manufacturing/social and environmental management and costs, in terms of social costs, was explained. Based on the abovementioned ideas, the problems encountered in the implementation of environmental management were discussed. It is important to enhance environmental protection awareness, especially in developing countries, to introduce environmental management systems effectively. In conclusion, with gradual implementation of the environmental and energy management system in Japan, operators have considerably reduced the emissions of GHGs, particularly $\mathrm{CO}_{2}$; however, priority should be given to countermeasures against global warming and to the positive promotion of energy conservation and environmental awareness to the general public especially in emerging and developing countries.

\section{Acknowledgments}

This research was supported by both a Grant-in-Aid for Asian CORE Program "Manufacturing and Environmental Management in East Asia" and a Grant-in-Aid 
Takakuwa, S.: A Perspective on Manufacturing and Environmental Management...

for Scientific Research (KAKENHI) of the Japan Society for the Promotion of Science (JSPS). This work was prepared by summarizing the partial results of these projects. The author wishes to express his sincere gratitude to the coauthors of Manufacturing and Environmental Management (Takakuwa, 2012).

\section{References}

Central Technology Support Center. (ed.) (2003). How to establish ISO14001 system, (2nd version), Tokyo: Nikkan Kogyo Shimbun. (in Japanese)

http://www.meti.go.jp/policy/eco_business/kaikeiWB/kaikeiWB-all.pdf (in Japanese) http://www.meti.go.jp/policy/eco_business/pdf/EMA(MFCA)-english\%20ppt.pdf Japan Environmental Management Association for Industry (JEMAI). Pollution control manager. Retrieved July 20, 2013, from http://133.242.7.244/english/index.html/

Ministry of Economy, Trade and Industry of Japan (METI). (2002). Environmental Management Accounting (EMA) Workbook (June 2002), Retrieved July 20, 2013, from Ministry of Economy, Trade and Industry of Japan (METI). (2007). Environmental Management Accounting (Material Flow Cost Accounting; MFCA). 2007, Retrieved July 20, 2013, from Ministry of Economy, Trade and Industry of Japan (METI). Retrieved July 20, 2013, from http://www.meti.go.jp/

Ministry of the Environment, Japan (MOEJ). (2009). Annual Report on the Environment, the Sound Material-Cycle Society and the Biodiversity in Japan (2009), Retrieved July 20, 2013, from http://www.env.go.jp/en/wpaper/ 2009/

Ministry of the Environment, Japan. (2009). EcoAction 21 Guidelines 2009, Retrieved July 20, 2013, from http://www.env.go.jp/policy/jhiroba/ea21/guideline2009_en.pdf

$\mathrm{Niu}, \mathrm{Z}$. and X. Fu. (2012). Investigation and analysis of environmental accounting in Chinese enterprises, Journal of Information and Management, Japan Society for Information and Management, Vol. 33, No.1, 123-127. (in Japanese)

Organization for Economic Co-operation and Development (OECD). Extended Producers Responsibility, Retrieved July 20, 2013, from http://oecd.org/document/19/0,3746,en_2649_34281_35158227_1_1_1_1,00.html Takakuwa, S. (ed.). (2012). Manufacturing and Environmental Management, Hanoi: National Political Publishing House

The Energy Conservation Center, Japan (ECCJ). Qualified Energy Manager. Retrieved July 20, 2013, from http://www.eccj.or.jp/

The Energy Conservation Center, Japan (ECCJ). The Act on the Rational and Relevant Laws on Energy Use (Energy Conservation Law), Retrieved July 20, 2013, from http://www.asiaeec-col.eccj.or.jp/brochure/index.html

The Institution of Professional Engineers, Japan (IPEJ). (2004). Comprehensive Management of Technology in Terms of Professional Engineers Systems, $2^{\text {nd }}$ ed., Tokyo 